\title{
Vitamin D and Gynecologic Outcomes: Insights from the EAGeR Trial
}

\author{
Thesis submission by \\ Daniel Kuhr, BS \\ MD Candidate May 2018 \\ University at Buffalo Jacobs School of Medicine and Biomedical Sciences \\ Mentor: Enrique Schisterman, PhD \\ Senior Investigator and Chief \\ Epidemiology Branch \\ Division of Intramural Population Health Research \\ Eunice Kennedy Shriver National Institute of Child Health and Human Development \\ National Institutes of Health \\ -and- \\ Volunteer Adjunct Professor \\ Department of Biostatistics \\ University at Buffalo
}

July 2017 


\begin{abstract}
Context: Vitamin D is associated with a host of reproductive outcomes, but there is little research investigating these relationships in healthy, regularly cycling, premenopausal women.

Objective: Our objective was to assess the relationship between vitamin D and hormonal biomarkers, sporadic anovulation, menstrual cycle length, and premenstrual syndrome and its symptoms. We hypothesize that vitamin $\mathrm{D}$ will be inversely associated with aberrations in reproductive and gynecologic function.
\end{abstract}

Methods: This was a prospective cohort of 1191 participants attempting to conceive, aged 18-40, with 1-2 prior pregnancy losses, no history of infertility, and enrolled in the EAGeR trial. Patients answered questionnaires regarding demographic information and gynecologic histories and serum samples were collected pre-randomization. Patients collected and froze daily first-void urine samples for up to two menstrual cycles. Patients were followed for risk of anovulation for two menstrual cycles and followed all together for up to six menstrual cycles.

Results: Vitamin D was associated with free androgen index and sex hormone binding globulin concentration, but not total testosterone, free testosterone, or dehydroepiandrosterone sulfate. Vitamin D was negatively associated with estrone-1-glucoronide in urine but not with pregnanediol glucuronide. Vitamin D was not associated with menstrual cycle length or its phase components and was not associated with risk of sporadic anovulation. Vitamin D was associated with breast tenderness/fullness and generalized aches and pains during the premenstrual week but not with other symptoms or overall risk of PMS.

Conclusions: Vitamin D may play a role in a host of reproductive and endocrine outcomes, including the bioavailability of androgens, concentrations of estrogens, and physical symptoms of PMS. 


\section{INTRODUCTION}

Vitamin D is well-known for its effects on bone health and metabolism. Vitamin D2 and D3 are hydroxylated by the liver to form 25-hydroxyvitamin D (25[OH]D) (1). This form is circulated in the bloodstream bound to a binding protein (2) and measured to clinically evaluate serum concentrations in humans (3). Further hydroxylation in the kidneys yields 1,25dihydroxyvitamin D (calcitriol), which is the most biologically active (4). It binds to vitamin D receptors (VDR) in the intestines to then promote the absorption of calcium $(5,6)$, promotes osteoclast resorption of bone, and is critical to normal parathyroid function (7). Yet vitamin D is involved in so much more than just calcium homeostasis. Vitamin D is also associated with a host of reproductive outcomes (8-10) and has receptors in the ovary, uterus, placenta, hypothalamus, and pituitary gland (11-13). The vitamin has been implicated in a number of pathologies affecting women, ranging from polycystic ovary syndrome (PCOS) to premenstrual syndrome (PMS), yet little is known about its function and relationships to various gynecologic and reproductive endpoints in healthy, regularly cycling women.

Vitamin D deficiency is defined by the Endocrine Society as serum 25(OH)D concentrations $<20.0 \mathrm{ng} / \mathrm{mL}$, and insufficiency is defined as a concentration $\geq 20.0 \mathrm{ng} / \mathrm{mL}$ but $<$ $30.0 \mathrm{ng} / \mathrm{mL}$ (14). NHANES data suggest that $46.1 \%$ of Americans are deficient in vitamin D (15). Among reproductive age women, vitamin D insufficiency has been reported in $26.8 \%$ of Quebecois women (16). Here in the United States, one study found that $2.0 \%$ and $44.9 \%$ of white and black pregnant women (4-21 weeks' gestation) were respectively vitamin D deficient while another $41.2 \%$ and $54.1 \%$ were respectively insufficient (17). Given the size of the population that does not have sufficient serum vitamin D concentrations, understanding all of its aberrant effects is critical for population health. Thus, the purpose of this work was to investigate vitamin D's 
relationship with various gynecologic and endocrinologic outcomes in healthy, premenopausal women. We hypothesize that insufficient vitamin D status is associated with aberrations in reproductive and gynecologic function: specifically, androgens, menstrual cycle function, and premenstrual syndrome.

\section{Vitamin D and Androgens}

Understanding ovulatory function is essential to understanding premenopausal women's health. We became interested in understanding vitamin D's influence on androgens because polycystic ovary syndrome (PCOS) is simultaneously the most common endocrinopathy in women worldwide (18) — specifically causing hyperandrogenism specifically — and the most common cause of ovulatory dysfunction (19). One small study of normal-BMI PCOS patients and healthy, non-obese women demonstrated a positive relationship between vitamin D and total testosterone (TT) (20) while another similar study found no relationship (21). Results among postmenopausal women show a negative relationship between vitamin D and TT $(22,23)$. Some studies have also investigated the bioavailability of testosterone. One study of 2931 postmenopausal women demonstrated a negative relationship between vitamin D and free testosterone (fT) (23). With regards to sex hormone binding globulin (SHBG)—which binds and limits the bioavailability of circulating free androgens and estrogens (24) - a positive relationship has been previously observed among both PCOS patients $(25,26)$ and postmenopausal women $(23,27)$.

There is also strong biological rationale for the association between vitamin $\mathrm{D}$ and the bioavailability of androgens mediated through SHBG. In particular, much prior work has focused on genetic variation in the vitamin D receptor (VDR), hyperandrogenism, and PCOS. Patients with at least one copy of the gene for VDR polymorphism Apa-I were more likely to have PCOS than 
those with none; those who were homozygous for the polymorphism were most likely to have PCOS (28). In a different study, Apa-I was associated with higher testosterone and androstenedione concentrations than other VDR polymorphisms, though these were attenuated after adjustment for vitamin D, calcium, BMI, and month of blood draw (29). A study of 260 PCOS patients and 221 normo-ovulatory controls found that when compared to normal genotype GG (guanine-guanine) those with single nucleotide polymorphisms of either one or two adenines (GA or AA) had a higher severity of PCOS but were not at increased risk for the disease itself (30). Finally, a study of 56 PCOS patients revealed that the VDR Bsm-I polymorphism was associated with lower SHBG concentrations (31), which is especially interesting since PCOS itself is associated with diminished concentrations of SHBG (32). While other methods of biologic interaction between vitamin D, SHBG, and androgens are possible, it seems likely that VDR polymorphisms play a role in linking vitamin D and its receptor function to the androgen-related biochemical and clinical features classically observed in PCOS. Specifically, if vitamin D insufficiency does influence SHBG homoeostasis, then total testosterone could remain unchanged while bioavailability would increase, therefore raising the potential for women to suffer from the physical effects of elevated androgens while having clinically "normal” total concentrations.

Exploring the normal physiologic relationships between vitamin D, SHBG, and androgens in healthy premenopausal women may help us understand this relationship more clearly since currently available data has only examined them in PCOS patients and postmenopausal women. Certainly, an improved understanding in the nonpathologic context may then inform our understanding of the pathophysiology of PCOS and shed light on future strategies to improve androgen excess. Therefore, we aimed to evaluate the relationship between vitamin D and androgen biomarkers in a large cohort of healthy, premenopausal women. 


\section{Vitamin D and Menstrual Cycle Function}

Since the pituitary gland has vitamin D receptors (33), it is also plausible that vitamin D may affect ovulation, follicular dynamics, and menstrual hormone levels; however, the data is sparse. The largest study suggesting a link between vitamin D and estrogens in postmenopausal women was suggested by results from the Multi-Ethnic Study of Atherosclerosis (MESA) (23), but little work has been done in premenopausal women. An analysis of data from the Nurses' Health Study II found no relationship between vitamin D intake and anovulatory infertility among 18,555 women (34). One previous pilot study suggested that metformin and vitamin D synergistically increase dominant follicle counts (35), but a larger trial ultimately found no improvement in follicle maturation or menstrual irregularities and infertility with metformin plus calcium and vitamin D supplementation. (36). Given that 3-18\% of menstrual cycles are sporadically anovulatory (37), and that anovulatory infertility is the most common cause of infertility (38), understanding the effect that vitamin D has on sporadic anovulation in healthy women is of critical importance to understanding the physiology of anovulation.

We know that menstrual cycle length is related to follicular phase estradiol concentrations, an earlier rise in follicle stimulating hormone, and increased risk of sporadic anovulation (39); however, there are large data gaps when it comes to vitamin D and menstrual cycle length, so we became particularly interested in this relationship as they may shed some light on the influence on hormonal dynamics. One study of African American women found vitamin D to be associated with reduced odds of long menstrual cycles, suggesting that vitamin D influences menstrual cycle length and may potentially play a role in ovarian function (40). Another study by the same research group found vitamin D levels to be associated with irregular menstrual cycles but with neither short nor long cycles (41). There is some data among PCOS patients to suggest that a relationship 
between menstrual cycle function exists. A pilot study evaluating calcium plus vitamin D supplementation in PCOS patients found no improvement in cycle regularity in groups taking both or both plus metformin compared to patients taking metformin alone (42). Another study of 13 PCOS patients undergoing vitamin D repletion plus calcium therapy found that normal menstrual cyclicity returned in 7 of the 13 women, suggesting that calcium homeostasis may be responsible for arrested follicular development in women with PCOS (43). Yet these results are not necessarily generalizable to wider populations of women, as the studies were small and PCOS only affects approximately $15-20 \%$ of women (44). Furthermore, few studies utilize serum vitamin D concentrations, instead relying on vitamin D intake; thus, we set out to utilize this approach to examine the relationships between vitamin D and menstrual cycle hormones, sporadic anovulation, and menstrual cycle length in healthy, regularly cycling women.

\section{Vitamin D and Premenstrual Syndrome}

Premenstrual syndrome (PMS) affects approximately $48 \%$ of women (45) and is associated with mild to severe psychological and physical symptoms that typically occur during the luteal phase of the menstrual cycle. Symptoms can affect normal day-to-day life, including activities and interpersonal relationships (46). PMS symptoms include but are not limited to: irritability, anxiety and depression, mood swings, breast tenderness, headaches, and bloating $(47,48)$.

Non-pharmaceutical therapies for PMS symptom relief, particularly related to dietary intake, are of great interest as they offer the potential for low-cost strategies to improve health and well-being. Hypocalcemia is known to cause symptoms that also occur in PMS, like muscle cramps, irritability, anxiety, and fatigue (49). Vitamin D has been proposed as an alternative because PMS is hypothesized to reflect a hypocalcemic state (50) and vitamin D plays a critical 
role in calcium metabolism and homeostasis. Vitamin D has also been hypothesized to improve dysmenorrhea through a reduction in proinflammatory cytokines (51). 1,25-dihydroxyvitamin D lowers cyclooxygenase-2 expression in endometrial tissue, leading to declines in prostaglandins, which are essential for menstrual cycle function (52). Vitamin D has anti-inflammatory properties and has been shown to deter prostaglandin function which may also play a role (53). Understanding interactions between the two in healthy women is essential for future work, thus we aimed to evaluate the relationship between serum vitamin D concentrations and PMS symptoms in healthy, regularly cycling women. 


\section{METHODS}

The EAGeR trial was a multicenter, block-randomized, double-blind, placebo controlled trial of daily low dose aspirin (LDA, $81 \mathrm{mg}$ ) in 1,228 women recruited from four U.S. medical centers from 2007 to 2011. Institutional Review Board approval was obtained at each study site and the data coordinating center. All participants provided written informed consent. The trial was registered with ClinicalTrials.gov, number NCT00467363. Full details of the study design, methods, and participant characteristics have been published elsewhere (54). The analyses presented here use the EAGeR trial cohort to answer important questions regarding the role of vitamin D on reproductive health outcomes.

\section{Study Design and Population}

Women trying to conceive who were 18-40 years old with regular menstrual cycles of 2142 days in length, documented confirmation of 1 or 2 prior pregnancy losses, and up to two prior live births were eligible for the EAGeR trial (54). Exclusion criteria for all women included, but were not limited to: clinical indication for use of anticoagulant therapy or chronic use of nonsteroidal anti-inflammatory drugs; bleeding disorders; presence of unstable mental disorders; major medical disorders (e.g. diabetes, hypertension, etc.); and any prior diagnosis of infertility or sub-fertility including related conditions such as PCOS, endometriosis, or pelvic inflammatory disease (54). Furthermore, all women must have been off long acting hormonal contraceptive medication (e.g. Depo-Provera, Norplant, intrauterine device) for at least 12 months or off oral contraceptive pills or other exogenous hormones (e.g. patch, ring) 3 months prior to enrollment. 


\section{Study Procedures}

Participants attended a baseline study visit prior to randomization timed to occur around day 2-4 of their menstrual cycle. During this baseline visit, participants completed questionnaires of reproductive health status and demographic and lifestyle factors. In addition, anthropometric measures and blood samples were collected. Samples were centrifuged and serum and plasma were aliquoted and frozen within 90 minutes. Samples were stored at $-80^{\circ} \mathrm{C}$ until analysis. Fertility monitors were provided to assist with timing of intercourse to optimize conception, evaluate ovulation status and scheduling subsequent study visits which were also timed to menstrual cycle phase (Clearblue Easy Fertility Monitor; Inverness Medical, Waltham, MA).

During the first two menstrual cycles of study participation, women collected daily first morning urine samples which were stored in a freezer and provided frozen to study staff at clinic visits, after which they were stored at $-80^{\circ} \mathrm{C}$ until analysis. Women were followed up for up to six menstrual cycles.

\section{Vitamin D Assessment}

Preconception 25-hydroxyvitamin D $(25(\mathrm{OH}) \mathrm{D})$ concentrations were measured in serum collected at baseline using the $25(\mathrm{OH}) \mathrm{D}$ ELISA solid phase sandwich enzyme immunoassay (BioVendor R\&D, Ashville, NC). The interassay laboratory coefficients of variation (CVs) were 15.8 and $13.1 \%$ at mean concentrations of 15.5 and $41.6 \mathrm{ng} / \mathrm{mL}$, respectively, for lyophilized manufacturer's controls, and $17 \%$ for an in-house pooled serum control. All values were above the lower limit of detection of $1.6 \mathrm{ng} / \mathrm{mL}$. 


\section{Outcome Measures}

Androgens

Total testosterone concentration (TT, ng/dL) was determined by liquid chromatography and tandem mass spectrometry using a Shimadzu Prominence Liquid Chromatogram (Shimadzu Scientific Instruments, Inc., Columbia, MD) with an ABSceix 5500 tandem mass spectrometer (AB SCIEX, Framingham, MA). Interassay coefficients of variance (CVs) were $2.0 \%$ at 189.81 and $1.4 \%$ at $809.54 \mathrm{ng} / \mathrm{mL}$. Free testosterone (fT) was calculated as $24.00314 \times \mathrm{TT} / \log _{10} \mathrm{SHBG}-$ $0.0499 \times \mathrm{TT}^{2}$ and free androgen index $(\mathrm{FAI})$ as $100 *(\mathrm{TT} / \mathrm{SHBG})$, where $\mathrm{TT}=$ total testosterone in $\mathrm{nmol} / \mathrm{L}$ and $\mathrm{SHBG}=$ sex hormone binding globulin in nmol/L (55). SHBG concentration was determined by SHBG reagent/sandwich immunoassay method/electrochemiluminescence (Roche Diagnostics, Indianapolis, IN) utilizing a Roche COBAS 6000 chemistry analyzer (Roche Diagnostics, Indianapolis, IN). Interassay $\mathrm{CVs}$ were $3.0 \%$ at $55.64 \mathrm{nmol} / \mathrm{L}$ and $3.8 \%$ at 19.74 nmol/L. Dehydroepiandrosterone sulfate (DHEAS) was determined by DHEA-S reagent/competitive immunoassay method/ electrochemiluminescence using a Roche COBAS 6000 chemistry analyzer (Roche Diagnostics, Indianapolis, IN). Interassay CVs were 4.6\% at 5.43 $\mu \mathrm{mol} / \mathrm{L}$ and $4.9 \%$ at $13.01 \mu \mathrm{mol} / \mathrm{L}$. Insulin was measured by sandwich immunoassay method using a Roche COBAS 6000 chemistry analyzer (Roche Diagnostics, Indianapolis, IN). Interassay CVs were $3.1 \%$ at $121.2 \mathrm{pmol} / \mathrm{L}$ and $3.1 \%$ at $377.9 \mathrm{pmol} / \mathrm{L}$.

\section{Menstrual Cycle Function}

Urinary measures were conducted at relevant menstrual cycle phases using daily firstmorning urine collected at home during the first two cycles of study participation. If women became pregnant during the first cycle, only their first cycle of urine measures were used. Estrone- 
3-glucuronide (E1G) and pregnanediol glucuronide (PdG) were determined by E1G/PdG Multiplex competitive chemiluminescence assay (Quansys Biosciences, Logan, UT). The interassay CVs for E1G were $16.9 \%$ and $20.2 \%$ at mean concentrations of $36.3 \mathrm{ng} / \mathrm{mL}$ and 1.9 $\mathrm{ng} / \mathrm{mL}$, respectively, for lyophilized manufacturer's controls and were $14.2 \%$ and $15.2 \%$ for inhouse pooled urine controls at mean concentrations of $23.7 \mathrm{ng} / \mathrm{mL}$ and $10.2 \mathrm{ng} / \mathrm{mL}$, respectively. The interassay CVs for PdG were $19.2 \%$ and $12.2 \%$ at mean concentrations of $1.986 \mu \mathrm{g} / \mathrm{mL}$ and $0.1069 \mu \mathrm{g} / \mathrm{mL}$ for lyophilized manufacturer's controls, respectively, and were $23.2 \%$ and $20.2 \%$ for in-house pooled urine controls at mean concentrations of 4.061 and $1.064 \mu \mathrm{g} / \mathrm{mL}$, respectively. Menstrual cycles ending in pregnancy were considered ovulatory. Anovulation was assessed using urinary hormone concentrations and fertility monitor data from the first two cycles of study participation among women who did not achieve a pregnancy in the first two cycles and was based on the following step by step algorithm.

1. Cycles with maximum luteal phase $\mathrm{PdG}<5 \mu \mathrm{g} / \mathrm{mL}$ were considered anovulatory ( $\mathrm{n}=259$ of 1,353 cycles) (56).

2. For cycles without an available luteal-phase PdG concentration, the cycle was considered anovulatory if the fertility monitor LH concentration was $<2.5$ times the average of the previous 5 days ( $\mathrm{n}=37$ of 147 cycles) (57).

3. Lastly, if adequate sequential LH data were unavailable from the fertility monitor, a peak fertility reading on the monitor was considered ovulatory $(\mathrm{n}=28)$ and all other cycles were unable to be classified $(\mathrm{n}=160)(58)$.

Cycle length was collected prospectively for all cycles of follow up (up to 6 prospective) and phase lengths were collected prospectively for two menstrual cycles. Cycle length was defined as the number of days between first days of menstrual bleeding. Follicular phase length was 
calculated as the number of days between the first day of menstrual bleeding and the expected ovulation day based on LH peak on a fertility monitor, and luteal phase length was calculated as the number of days between LH peak on the monitor and the day prior to onset of next menses.

\section{Premenstrual Syndrome}

Participants completed a questionnaire at baseline detailing five psychological symptoms (depression or sadness, tension or irritability, anxiety or nervousness, anger or aggression or short temper, and crying spells), and nine physical symptoms (swelling of hands or feet, breast tenderness or fullness, abdominal bloating, lower abdominal cramping, generalized aches and pains, lower backache, headache, fatigue, and insomnia) that were associated with PMS over the past 12 months. They rated their symptoms in the past 12 months during a typical week leading up to menses on a scale of: $0=$ none, $1=$ mild, $2=$ moderate, or $3=$ severe. A total symptom severity score was calculated by adding the severity ratings for all symptoms (total possible score 42). Scores were calculated for the week prior to menses and the week after menses for comparison and assessment of PMS. Participants were then denoted as either having moderate/severe or mild/none for each symptom during the premenstrual week. The total number of moderate/severe symptoms during the premenstrual week was calculated overall and by symptom type.

Two different sets of criteria were used to define PMS:

1. Women with $\geq 3$ moderate to severe symptoms during premenstrual week with a minimum of 1 being psychological, and a total symptom severity score during the premenstrual week at least $30 \%$ greater than the total symptom severity score during the postmenstrual week, were categorized as having PMS. This set of criteria was adapted from Borenstein et al. and used in other studies as well (59-61). 
2. Women with $\geq 5$ moderate to severe symptoms during premenstrual week, with at least 2 being psychological, and a total symptom severity score during the premenstrual week at least $30 \%$ greater than the total symptom severity score during the postmenstrual week, were categorized as having PMS. This set of criteria reflects more severe premenstrual symptoms as used by Gollenberg et al. (61).

\section{Statistical Analysis}

Participants were determined to be vitamin D-sufficient $(25(\mathrm{OH}) \mathrm{D} \geq 30.0 \mathrm{ng} / \mathrm{mL})$ or vitamin D-insufficient $(25(\mathrm{OH}) \mathrm{D}<30.0 \mathrm{ng} / \mathrm{mL})$ using baseline $25(\mathrm{OH}) \mathrm{D}$ serum concentrations (14). Demographic and reproductive histories at baseline were compared by vitamin D status using student's t-tests and chi-square tests where appropriate. SAS version 9.4 (SAS Institute, Cary, North Carolina) was used for all statistical analysis.

\section{Androgens}

Generalized linear regression was used to estimate the associations between baseline vitamin D and TT, fT, FAI, DHEAS, and SHBG. All hormonal markers were natural logtransformed to achieve normal distributions, and thus results are reported as percent change in the dependent variable per unit change in independent variable with 95\% CI (62). Models were adjusted for age, BMI, current smoking status, race, income, physical activity, and season of blood draw. Models for SHBG were additionally adjusted for TT, E1G, and insulin, as they are known to affect SHBG concentrations (63). Androgen models were not adjusted for treatment arm as the serum was collected prior to randomization. 


\section{Menstrual Cycle Function}

Linear mixed models were used to prospectively evaluate associations between vitamin D and follicular phase E1G and luteal phase PdG accounting for multiple measures per woman over both cycles of follow up. Both E1G and PdG were natural log-transformed to achieve normal distributions, and thus results are reported as percent change in the dependent variable per unit change in independent variable with 95\% CI (62). Models were adjusted for age, BMI, current smoking status, race, income, physical activity, season of blood draw, and treatment arm.

Log-binomial regression was used to prospectively estimate the risk ratios (RR) and 95\% confidence intervals (CI) for sporadic anovulation during the first two cycles of study participation, taking into account multiple cycles per woman. Models were adjusted for age, BMI, current smoking status, race, income, physical activity, season of blood draw, and treatment arm.

Linear mixed models were used to prospectively evaluate the relationships between vitamin D and follicular phase, and luteal phase lengths across 2 prospective cycles of follow up. Linear mixed models were also used to evaluate the relationship between total cycle length and vitamin D for up to 6 cycles of follow up and were weighted to account for number of cycles each participant contributed. Cycles ending in pregnancy were excluded from the analysis. Models were adjusted for age, BMI, current smoking status, race, income, physical activity, season of blood draw, and treatment arm.

\section{Premenstrual Syndrome}

Log-binomial regression was used to estimate the RR and 95\% CI for both PMS criteria and for the individual symptoms of moderate/severe intensity during the premenstrual week. Logistic regression was used estimate the odds ratio (OR) and 95\% CI for swelling of the hands 
and feet due to lack of power. Generalized linear regression was used to calculate the $\beta$-coefficient and $95 \% \mathrm{CI}$ for the association between vitamin $\mathrm{D}$ and total number of moderate/severe symptoms, total number of moderate/severe psychological symptoms, and total number of moderate/severe physical symptoms. All models were adjusted for age, BMI, current smoking status, race, income, physical activity, season of blood draw. Models were not adjusted for treatment arm as the questionnaires were filled out and serum collected prior to randomization. 


\section{RESULTS}

Vitamin D data was available for 1191 patients, for whom the demographic characteristics and gynecologic histories are provided in Table 1. Of the 1191 patients, 555 had sufficient and 636 had insufficient serum vitamin D concentrations. A higher proportion of women with sufficient vitamin D were white than vitamin D-insufficient women. Women with sufficient vitamin D also had lower BMI and smaller waist circumference, sum of skinfolds, and central-to-peripheral skinfold ratio than those with insufficient concentrations. There we no differences between both groups' reported gynecologic histories.

\section{Androgens}

Vitamin D was not associated with TT and DHEAS (Table 2). However, vitamin D was negatively associated with fT in the unadjusted model, but this relationship was attenuated after adjustment for potential confounders. Vitamin D concentration was negatively associated with FAI. Vitamin D concentration was positively associated with SHBG concentration. These findings remained consistent after additional adjustment for TT, E1G and insulin.

\section{Menstrual Cycle Function}

There was a negative relationship between E1G and vitamin D but no relationship between PdG and vitamin D (Table 2).

$14.6 \%$ of participants experienced a sporadic anovulatory cycle in the first two cycles of follow up, with $13.1 \%$ of vitamin D sufficient and $15.1 \%$ of insufficient patients experiencing one. Vitamin D was not associated with the risk of sporadic anovulation (Table 3). 
The mean menstrual cycle length was 30.1 days and 31.3 days for vitamin D sufficient and insufficient women, respectively. The respective mean follicular phase lengths for sufficient and insufficient groups were 15.3 and 15.4, and the luteal phase length means were 13.4 and 13.2 days, respectively. There were no significant relationships between vitamin D and menstrual cycle length, follicular phase length, or luteal phase length in the continuous vitamin D models. Vitamin D insufficiency was associated with menstrual cycle length but the results were attenuated after adjustment or confounders (Table 4).

\section{Premenstrual Syndrome}

Vitamin D concentrations and PMS data were available for 1139 participants. $39.2 \%$ of women with sufficient vitamin D and $41.9 \%$ of women with insufficient vitamin D met the first set of criteria for PMS, while $23.4 \%$ and $24.8 \%$ respectively met the second criteria. The most common physical symptom reported was lower abdominal cramping, which was experienced by $37 \%$ of women, following by abdominal bloating (34.1\%) and fatigue (30.8\%). The most common psychological PMS symptom reported was tension or irritability (40.6\%), followed by anger, aggression, and short temper (28.6\%). Vitamin D was not associated with risk of PMS based on either of the two sets of criteria. Vitamin D was associated with the total number of premenstrual symptoms, but the relationship was attenuated after adjustment in both categorical and continuous models (Table 5).

Vitamin D insufficiency was associated with number of moderate/severe physical symptoms, though results in the continuous models were attenuated after adjustment. Vitamin D was associated with increased risk of breast tenderness or fullness and generalized aches and pains. There was no relationship between vitamin D and abdominal bloating, cramping, and fatigue, 
swelling of the hands and feet, headache or insomnia after adjustment for confounders (Table 6). There were no significant relationships with vitamin D and either number of psychological symptoms or individual psychological symptoms of PMS (Table 7). 


\section{TABLES}

Table 1. Characteristics of women in the EAGeR trial by vitamin D status at baseline.

\begin{tabular}{|c|c|c|c|}
\hline & Vitami & Status & \\
\hline & $\begin{array}{l}\text { Vitamin D Sufficient } \\
\quad(\geq 30 \mathrm{ng} / \mathrm{mL})\end{array}$ & $\begin{array}{c}\text { Vitamin D Insufficient } \\
(<30 \mathrm{ng} / \mathrm{mL})\end{array}$ & p-value \\
\hline & $\mathrm{N}=555$ & $\mathrm{~N}=636$ & \\
\hline Age, mean \pm SD (years) & $28.9 \pm 4.8$ & $28.6 \pm 4.8$ & 0.36 \\
\hline BMI, mean $\pm \mathrm{SD}\left(\mathrm{kg} / \mathrm{m}^{2}\right)$ & $24.5 \pm 5.06$ & $27.8 \pm 7.3$ & $<0.0001$ \\
\hline Waist circumference, mean $\pm S D(\mathrm{~cm})$ & $82.7 \pm 12.3$ & $90.5 \pm 16.6$ & $<0.0001$ \\
\hline Sum of skinfolds, mean \pm SD $(\mathrm{mm})$ & $92.0 \pm 27.6$ & $108.2 \pm 35.1$ & $<0.0001$ \\
\hline $\begin{array}{l}\text { Central to peripheral skinfold ratio, mean } \pm \\
\text { SD }\end{array}$ & $0.7 \pm 0.2$ & $0.8 \pm 0.2$ & $<0.0001$ \\
\hline Race, $\mathbf{n}(\%)$ & & & $<0.0001$ \\
\hline White & $542(98 \%)$ & $586(92 \%)$ & \\
\hline Non-White & $13(2 \%)$ & $50(8 \%)$ & \\
\hline Married or living with partner, n (\%) & $542(98 \%)$ & $620(97 \%)$ & 0.85 \\
\hline Education > high school, n (\%) & $491(89 \%)$ & $542(85 \%)$ & 0.08 \\
\hline Income, $n(\%)$ & & & 0.0004 \\
\hline$\geq \$ 100,000$ & $209(38 \%)$ & $261(41 \%)$ & \\
\hline$\$ 75,000-\$ 99,999$ & $84(15 \%)$ & $63(10 \%)$ & \\
\hline$\$ 40,000-\$ 74,999$ & $99(18 \%)$ & $75(12 \%)$ & \\
\hline$\$ 20,000-\$ 39,999$ & $128(23 \%)$ & $179(28 \%)$ & \\
\hline$\leq \$ 19,999$ & $35(6 \%)$ & $57(9 \%)$ & \\
\hline Current smokers, n (\%) & $69(13 \%)$ & $79(13 \%)$ & 0.99 \\
\hline Parity, n (\%) & & & 0.09 \\
\hline Nulliparous & $271(49 \%)$ & $279(44 \%)$ & \\
\hline Parous ( 1 or 2 prior live births) & $284(51 \%)$ & $357(56 \%)$ & \\
\hline Number of previous pregnancy losses, $n(\%)$ & & & 0.84 \\
\hline 1 & $211(33 \%)$ & $425(67 \%)$ & \\
\hline 2 & $181(33 \%)$ & $374(67 \%)$ & \\
\hline $\begin{array}{l}\text { Ever used hormonal contraception/meds, any } \\
\text { reason, } n(\%)\end{array}$ & $435(82)$ & $472(79 \%)$ & 0.24 \\
\hline Years for periods to become regular & $1.5(4.2 \%)$ & $1.7(4.3 \%)$ & 0.4824 \\
\hline Usual menstrual bleeding, $d$ & $5.0(1.3 \%)$ & $5.1(2.1 \%)$ & 0.5192 \\
\hline Number of periods in past 6 months & $4.6(1.6 \%)$ & $4.6(1.6 \%)$ & 0.376 \\
\hline Regular periods, $\mathbf{n}(\%)$ & & & 0.0628 \\
\hline Yes & $439(82 \%)$ & $500(84 \%)$ & \\
\hline No & $77(14 \%)$ & $61(10 \%)$ & \\
\hline Don't Know & $22(4 \%)$ & $34(6 \%)$ & \\
\hline Age at menarche, years & $12.8(1.5)$ & $12.7(1.5)$ & 0.21 \\
\hline Aspirin treatment assignment, n (\%) & $285(51 \%)$ & $313(49 \%)$ & 0.46 \\
\hline
\end{tabular}

$\mathrm{SD}=$ standard deviation $; \mathrm{n}=$ number 
Table 2. Associations between vitamin D and androgen concentrations and other endocrine characteristics among women in the EAGeR trial.

\begin{tabular}{|c|c|c|c|}
\hline & $\begin{array}{l}\text { Vitamin D Sufficient } \\
(\geq 30 \mathrm{ng} / \mathrm{mL})\end{array}$ & $\begin{array}{c}\text { Vitamin D Insufficient } \\
(<30 \mathrm{ng} / \mathrm{mL})\end{array}$ & $\begin{array}{c}\text { Vitamin D } \\
(\text { per } 10 \mathrm{ng} / \mathrm{mL})\end{array}$ \\
\hline \multicolumn{4}{|l|}{ Serum Measurements } \\
\hline \multicolumn{4}{|l|}{ Total testosterone (TT) } \\
\hline Mean \pm SD $(\mathrm{ng} / \mathrm{dL})$ & $22.1 \pm 12.0$ & $22.5 \pm 9.7$ & \\
\hline Unadjusted percent change (95\% CI) & Reference & $3 \%(-2 \%, 8 \%)$ & $-2 \%(-4 \%, 0.2 \%)$ \\
\hline Adjusted percent change (95\% CI) & Reference & $0 \%(-5 \%, 5 \%)$ & $0 \%(-2 \%, 2 \%)$ \\
\hline \multicolumn{4}{|l|}{ Free testosterone (fT) } \\
\hline Mean \pm SD $(n g / d L)$ & $0.3 \pm 0.2$ & $0.3 \pm 0.1$ & \\
\hline Unadjusted percent change (95\% CI) & Reference & $9 \%(4 \%, 13 \%)$ & $-4 \%(-6 \%,-2 \%)$ \\
\hline Adjusted percent change ( $95 \% \mathrm{CI})$ & Reference & $2 \%(-2,7)$ & $-2 \%(-4 \%, 0.4 \%)$ \\
\hline \multicolumn{4}{|l|}{ Free Androgen Index (FAI) } \\
\hline Mean \pm SD & $1.2 \pm 0.9$ & $1.6 \pm 1.2$ & \\
\hline Unadjusted percent change (95\% CI) & Reference & $25 \%(18 \%, 31 \%)$ & $-11 \%(-14 \%,-8 \%)$ \\
\hline Adjusted percent change $(95 \% \mathrm{CI})$ & Reference & $10 \%(3 \%, 16 \%)$ & $-5 \%(-8 \%,-2 \%)$ \\
\hline \multicolumn{4}{|l|}{ DHEAS } \\
\hline Mean \pm SD $(\mu \mathrm{mol} / \mathrm{L})$ & $4.8 \pm 2.2$ & $5.1 \pm 2.6$ & \\
\hline Unadjusted percent change (95\% CI) & Reference & $4 \%(-2,10)$ & $-2 \%(-4 \%, 0.5 \%)$ \\
\hline Adjusted percent change $(95 \% \mathrm{CI})$ & Reference & $1 \%(-5 \%, 7 \%)$ & $-1 \%(-3 \%, 2 \%)$ \\
\hline \multicolumn{4}{|l|}{ SHBG } \\
\hline Mean \pm SD $(\mathrm{nmol} / \mathrm{L})$ & $75.1 \pm 36.1$ & $61.2 \pm 31.4$ & \\
\hline Unadjusted percent change $(95 \% \mathrm{CI})$ & Reference & $-21 \%(-27 \%,-16 \%)$ & $9 \%(7 \%, 11 \%)$ \\
\hline Adjusted percent change $(95 \% \mathrm{CI})$ & Reference & $-10 \%(-15 \%,-4 \%)$ & $4 \%(2 \%, 7 \%)$ \\
\hline Additional adjustment for insulin, TT, and E1G & Reference & $-10 \%(-16 \%,-4 \%)$ & $7 \%(4 \%, 10 \%)$ \\
\hline \multicolumn{4}{|l|}{ Urinary hormones } \\
\hline \multicolumn{4}{|l|}{$\begin{array}{l}\text { Estrone-3-Glucoronide (E1G), follicular } \\
\text { phase }\end{array}$} \\
\hline Mean $\pm \mathrm{SD}(\mathrm{ng} / \mathrm{mL})$ & $30.5 \pm 26.3$ & $33.2 \pm 34.1$ & \\
\hline Unadjusted percent change (95\% CI) & Reference & $6 \%(-4 \%, 17 \%)$ & $-7 \%(-12 \%,-2 \%)$ \\
\hline Adjusted percent change $(95 \% \mathrm{CI})$ & Reference & $2 \%(-9 \%, 13 \%)$ & $-5 \%(-10 \%,-0.2 \%)$ \\
\hline \multicolumn{4}{|l|}{$\begin{array}{l}\text { Pregnanediol-3-Glucoronide (PdG), luteal } \\
\text { phase }\end{array}$} \\
\hline Mean $\pm \mathrm{SD}(\mu \mathrm{g} / \mathrm{mL})$ & $20.7 \pm 30.5$ & $23.3 \pm 114.1$ & \\
\hline Unadjusted percent change (95\% CI) & Reference & $-5 \%(-17 \%, 6 \%)$ & $-2 \%(-7 \%, 3 \%)$ \\
\hline Adjusted percent change $(95 \% \mathrm{CI})$ & Reference & $-5 \%(-17 \%, 7 \%)$ & $-2 \%(-7 \%, 4 \%)$ \\
\hline
\end{tabular}

$\mathrm{SD}=$ standard deviation; $\mathrm{CI}=$ confidence interval.

Bold results are statistically significant at $\alpha=0.05$.

Adjusted models control for age, body mass index, smoking status, race, income, exercise, season of blood draw.

Adjusted E1G and PdG models also control for treatment arm as those data were collected prospectively after randomization. 
Table 3. Association between vitamin D and sporadic anovulation among women in the EAGeR trial.

\begin{tabular}{lccc}
\hline & $\begin{array}{c}\text { Vitamin D Sufficient } \\
(\geq \mathbf{3 0} \mathbf{~ n g} / \mathbf{m L})\end{array}$ & $\begin{array}{c}\text { Vitamin D Insufficient } \\
(<\mathbf{3 0} \mathbf{~ n g} / \mathbf{m L})\end{array}$ & $\begin{array}{c}\text { Vitamin D } \\
(\text { per 10 } \mathbf{~ n g} / \mathbf{m L})\end{array}$ \\
\hline Incidence of sporadic anovulation & $13.1 \%$ & $15.1 \%$ & \\
Unadjusted RR (95\% CI) & Reference & $1.23(0.97,1.56)$ & $0.97(0.87,1.08)$ \\
Adjusted RR (95\% CI) & Reference & $1.04(0.81,1.34)$ & $1.04(0.94,1.15)$ \\
\hline
\end{tabular}

$\mathrm{RR}=$ risk ratio; $\mathrm{CI}=$ confidence interval.

Bold results are significant at $\alpha=0.05$.

Adjusted models control for age, body mass index, smoking status, race, income, exercise, season of blood draw, and treatment arm. 
Table 4. Associations between vitamin D and menstrual cycle and phase lengths

\begin{tabular}{lccc}
\hline & $\begin{array}{c}\text { Vitamin D Sufficient } \\
(\geq 30 \mathrm{ng} / \mathrm{mL})\end{array}$ & $\begin{array}{c}\text { Vitamin D Insufficient } \\
(<30 \mathrm{ng} / \mathrm{mL})\end{array}$ & $\begin{array}{c}\text { Vitamin D } \\
(\text { per } 10 \mathrm{ng} / \mathrm{mL})\end{array}$ \\
\hline Cycle length & & & \\
Mean \pm SD (days) & $30.1 \pm 6.6$ & $31.3 \pm 10.5$ & \\
Unadjusted, $\beta(95 \% \mathrm{CI})$ & Reference & $\mathbf{0 . 8 8}(\mathbf{0 . 2 1}, \mathbf{1 . 5 4})$ & $-0.19(-0.46,0.09)$ \\
Adjusted, $\beta$ (95\% CI) & Reference & $0.59(-0.10,1.28)$ & $-0.03(-0.32,0.26)$ \\
Follicular phase length & & & \\
Mean \pm SD (days) & $15.3 \pm 2.7$ & $15.4 \pm 2.8$ & \\
Unadjusted, $\beta$ (95\% CI) & Reference & $0.14(-0.18,0.38)$ & $0.03(-0.08,0.16)$ \\
Adjusted, $\beta$ (95\% CI) & Reference & $0.03(-0.27,0.32)$ & $0.06(-0.07,0.19)$ \\
Luteal phase length & & & \\
Mean \pm SD (days) & & & \\
Unadjusted, $\beta$ (95\% CI) & $13.4 \pm 4.7$ & $13.2 \pm 4.4$ & \\
Adjusted, $\beta$ (95\% CI) & Reference & $-0.21(-0.67,0.25)$ & $-0.07(-0.26,0.13)$ \\
\hline
\end{tabular}

$\mathrm{SD}=$ standard deviation $; \mathrm{CI}=$ confidence interval .

Bold results are significant at $\alpha=0.05$.

Adjusted models control for age, BMI, smoking status, race, income, exercise, season of blood draw, and treatment arm. 
Table 5. Associations between vitamin D and premenstrual syndrome

\begin{tabular}{lccc}
\hline & $\begin{array}{c}\text { Vitamin D Sufficient } \\
(\geq \mathbf{3 0} \mathbf{~ n g} / \mathbf{m L})\end{array}$ & $\begin{array}{c}\text { Vitamin D Insufficient } \\
(\leq \mathbf{3 0} \mathbf{~ n g} / \mathbf{m L})\end{array}$ & $\begin{array}{c}\text { Vitamin D } \\
(\mathbf{p e r} \mathbf{1 0} \mathbf{~ n g} / \mathbf{m L})\end{array}$ \\
\hline PMS Criteria 1 & & & \\
Prevalence & $39.2 \%$ & $41.9 \%$ & \\
Unadjusted RR (95\% CI) & Ref & $1.07(0.93,1.23)$ & $1.00(0.93,1.06)$ \\
Adjusted RR (95\% CI) & Ref & $1.02(0.88,1.18)$ & $1.02(0.96,1.09)$ \\
PMS Criteria 2 & & & \\
Prevalence & $23.4 \%$ & $24.8 \%$ & $0.96(0.88,1.05)$ \\
Unadjusted RR (95\% CI) & Ref & $1.06(0.86,1.30)$ & $1.00(0.92,1.10)$ \\
Adjusted RR (95\% CI) & Ref & $0.94(0.76,1.17)$ & \\
Number of Moderate/Severe & & & \\
Premenstrual Symptoms & & & \\
Mean + SD & $3.0 \pm 2.9$ & $3.5 \pm 3.2$ & $\mathbf{- 0 . 1 6}(-\mathbf{- 0 . 3 1}, \mathbf{- 0 . 0 1 )}$ \\
Unadjusted $\beta$ (95\% CI) & Ref & $\mathbf{0 . 4 9}(\mathbf{0 . 1 3}, \mathbf{0 . 8 5})$ & $-0.08(-0.24,0.07)$ \\
Adjusted $\beta$ (95\% CI) & Ref & & \\
\hline
\end{tabular}

$\mathrm{RR}=$ risk ratio $; \mathrm{CI}=$ confidence interval $; \mathrm{SD}=$ standard deviation

\section{Bold results are significant at $\alpha=0.05$}

Adjusted models control for age, BMI, smoking status, race, income, exercise, season of blood draw

PMS criteria 1: $\geq 3$ moderate to severe symptoms during premenstrual week (minimum of 1 psychological), and a total of symptom severity during premenstrual week at least $30 \%$ greater than the total score during the postmenstrual week (59-61).

PMS criteria 2: $\geq 5$ moderate to severe symptoms during premenstrual week (at least 2 psychological), and a total of symptom severity score during premenstrual week at least $30 \%$ greater than the total score during the postmenstrual week (61). 
Table 6. Associations between vitamin D and physical symptoms of PMS

\begin{tabular}{|c|c|c|c|}
\hline & $\begin{array}{c}\text { Vitamin D Sufficient } \\
(\geq 30 \mathrm{ng} / \mathrm{mL})\end{array}$ & $\begin{array}{c}\text { Vitamin D Insufficient } \\
(<30 \mathrm{ng} / \mathrm{mL})\end{array}$ & $\begin{array}{c}\text { Vitamin D } \\
(\text { per } 10 \mathrm{ng} / \mathrm{mL})\end{array}$ \\
\hline \multicolumn{4}{|c|}{ Number of Moderate/Severe } \\
\hline \multicolumn{4}{|l|}{ Physical Symptoms } \\
\hline Mean + SD & $1.9 \pm 2.0$ & $2.3 \pm 2.3$ & \\
\hline Unadjusted $\beta$ (95\% CI) & Ref & $0.42(0.17,0.67)$ & $-0.15(-0.25,-0.05)$ \\
\hline Adjusted $\beta(95 \% \mathrm{CI})$ & Ref & $0.31(0.06,0.51)$ & $-0.10(-0.20,0.01)$ \\
\hline \multicolumn{4}{|l|}{ Swelling of Hands or Feet } \\
\hline Prevalence & $3.1 \%$ & $5.4 \%$ & \\
\hline Unadjusted OR* $(95 \% \mathrm{CI})$ & Ref & $1.75(0.96,3.18)$ & $0.76(0.56,1.02)$ \\
\hline Adjusted OR* (95\% CI) & Ref & $1.67(0.87,3.23)$ & $0.78(0.56,1.08)$ \\
\hline \multicolumn{4}{|c|}{ Breast Tenderness or Fullness } \\
\hline Prevalence & $23.5 \%$ & $31.2 \%$ & \\
\hline Unadjusted RR (95\% CI) & Ref & $1.33(1.10,1.61)$ & $0.87(0.79,0.95)$ \\
\hline Adjusted RR (95\% CI) & Ref & $1.27(1.03,1.55)$ & $0.89(0.81,0.98)$ \\
\hline \multicolumn{4}{|l|}{ Abdominal Bloating } \\
\hline Prevalence & $31.2 \%$ & $36.6 \%$ & \\
\hline Unadjusted RR (95\% CI) & Ref & $1.17(0.995,1.38)$ & $0.94(0.88,1.01)$ \\
\hline Adjusted RR (95\% CI) & Ref & $1.17(0.98,1.39)$ & $0.95(0.88,1.03)$ \\
\hline \multicolumn{4}{|c|}{ Lower Abdominal Cramping } \\
\hline Prevalence & $32.9 \%$ & $40.3 \%$ & \\
\hline Unadjusted RR (95\% CI) & Ref & $1.22(1.05,1.43)$ & $0.93(0.86,1.001)$ \\
\hline Adjusted RR (95\% CI) & Ref & $1.13(0.96,1.33)$ & $0.97(0.90,1.04)$ \\
\hline \multicolumn{4}{|c|}{ Generalized Aches and Pains } \\
\hline Prevalence & $13.5 \%$ & $20.4 \%$ & \\
\hline Unadjusted RR (95\% CI) & Ref & $1.52(1.16,1.98)$ & $0.81(0.71,0.93)$ \\
\hline Adjusted RR (95\% CI) & Ref & $1.33(1.005,1.78)$ & $0.87(0.76,0.99)$ \\
\hline \multicolumn{4}{|l|}{ Lower Backache } \\
\hline Prevalence & $20.7 \%$ & $26.3 \%$ & \\
\hline Unadjusted RR (95\% CI) & Ref & $1.27(1.03,1.57)$ & $0.95(0.87,1.05)$ \\
\hline Adjusted RR (95\% CI) & Ref & $1.19(0.95,1.48)$ & $0.99(0.90,1.09)$ \\
\hline \multicolumn{4}{|l|}{ Headache } \\
\hline Prevalence & $26.0 \%$ & $25.8 \%$ & \\
\hline Unadjusted RR (95\% CI) & Ref & $0.99(0.81,1.21)$ & $0.97(0.89,1.06)$ \\
\hline Adjusted RR (95\% CI) & Ref & $0.94(0.76,1.16)$ & $1.00(0.92,1.09)$ \\
\hline \multicolumn{4}{|l|}{ Fatigue } \\
\hline Prevalence & $28.1 \%$ & $33.2 \%$ & \\
\hline Unadjusted RR (95\% CI) & Ref & $1.18(0.99,1.41)$ & $0.93(0.85,1.01)$ \\
\hline Adjusted RR (95\% CI) & Ref & $1.09(0.90,1.31)$ & $0.97(0.89,1.05)$ \\
\hline \multicolumn{4}{|l|}{ Insomnia } \\
\hline Prevalence & $8.5 \%$ & $10.5 \%$ & \\
\hline Unadjusted RR (95\% CI) & Ref & $1.24(0.86,1.78)$ & $0.93(0.79,1.10)$ \\
\hline Adjusted RR (95\% CI) & Ref & $1.14(0.78,1.67)$ & $0.97(0.83,1.15)$ \\
\hline
\end{tabular}

$\mathrm{SD}=$ standard deviation; $\mathrm{RR}=$ risk ratio

Bold results are significant at $\alpha=0.05$

Adjusted models control for age, BMI, smoking status, race, income, exercise, season of blood draw.

*Logistic regression was used to odds ratios (OR) due to lack of power. 
Table 7. Associations between vitamin D and psychological symptoms of PMS.

\begin{tabular}{|c|c|c|c|}
\hline & $\begin{array}{c}\text { Vitamin D Sufficient } \\
(\geq 30 \mathrm{ng} / \mathrm{mL})\end{array}$ & $\begin{array}{c}\text { Vitamin D Insufficient } \\
(<30 \mathrm{ng} / \mathrm{mL})\end{array}$ & $\begin{array}{c}\text { Vitamin D } \\
(\text { per } 10 \mathrm{ng} / \mathrm{mL})\end{array}$ \\
\hline \multicolumn{4}{|c|}{ Number of Moderate/Severe } \\
\hline \multicolumn{4}{|l|}{ Psychological Symptoms } \\
\hline Mean + SD & $1.2 \pm 1.5$ & $1.2 \pm 1.5$ & \\
\hline Unadjusted $\beta(95 \% \mathrm{CI})$ & Ref & $0.07(-0.11,0.25)$ & $-0.01(-0.08,0.06)$ \\
\hline Adjusted $\beta(95 \% \mathrm{CI})$ & Ref & $0.02(-0.17,0.21)$ & $0.01(-0.07,0.09)$ \\
\hline \multicolumn{4}{|l|}{ Depression or Sadness } \\
\hline Prevalence & $16.8 \%$ & $17.9 \%$ & \\
\hline Unadjusted RR (95\% CI) & Ref & $1.06(0.83,1.37)$ & $1.01(0.92,1.12)$ \\
\hline Adjusted RR (95\% CI) & Ref & $1.07(0.82,1.40)$ & $0.99(0.90,1.12)$ \\
\hline \multicolumn{4}{|l|}{ Tension or Irritability } \\
\hline Prevalence & $39.8 \%$ & $41.3 \%$ & \\
\hline Unadjusted RR (95\% CI) & Ref & $1.04(0.90,1.20)$ & $0.99(0.93,1.05)$ \\
\hline Adjusted RR (95\% CI) & Ref & $1.00(0.86,1.16)$ & $1.00(0.94,1.07)$ \\
\hline \multicolumn{4}{|l|}{ Anxiety or Nervousness } \\
\hline Prevalence & $17.9 \%$ & $19.4 \%$ & \\
\hline Unadjusted RR (95\% CI) & Ref & $1.09(0.85,1.38)$ & $1.03(0.93,1.14)$ \\
\hline Adjusted RR (95\% CI) & Ref & $1.06(0.82,1.36)$ & $1.04(0.94,1.16)$ \\
\hline \multicolumn{4}{|c|}{ Anger, Aggression, Short Temper } \\
\hline Prevalence & $28.5 \%$ & $28.6 \%$ & \\
\hline Unadjusted RR (95\% CI) & Ref & $1.00(0.84,1.21)$ & $0.96(0.89,1.04)$ \\
\hline Adjusted RR (95\% CI) & Ref & $0.93(0.77,1.13)$ & $1.00(0.92,1.08)$ \\
\hline \multicolumn{4}{|l|}{ Crying Spells } \\
\hline Prevalence & $13.9 \%$ & $16.8 \%$ & \\
\hline Unadjusted RR (95\% CI) & Ref & $1.21(0.92,1.60)$ & $0.96(0.85,1.09)$ \\
\hline Adjusted RR (95\% CI) & Ref & $1.11(0.83,1.48)$ & $1.00(0.88,1.13)$ \\
\hline
\end{tabular}

$\mathrm{SD}=$ standard deviation; $\mathrm{RR}=$ relative risk; $\mathrm{CI}=$ confidence interval.

Bold results are significant at $\alpha=0.05$.

Adjusted models control for age, BMI, smoking status, race, income, exercise, season of blood draw, and treatment arm. 


\section{DISCUSSION}

Androgens

Our results show increasing vitamin D concentrations were negatively associated with FAI and positively associated with SHBG in this cohort of healthy, premenopausal women with no diagnosis of infertility or PCOS. The positive relationship between vitamin D and SHBG is likely driving the negative relationship we observed with FAI, since FAI is calculated using serum concentration of SHBG. These results help elucidate the role vitamin D may play in the bioavailability of androgens, a potentially important factor in the pathophysiology of hyperandrogenism and its related complications for women of reproductive age. It is possible that women with biochemically "normal" total testosterone levels could still suffer from [mild] aberrant effects of testosterone if it is more bioavailable due to suboptimal vitamin D concentrations. However, it is important to note that our data regarding vitamin D and androgens is cross-sectional, so no conclusions as to how changes in vitamin D affect the bioavailability of androgens over time can be drawn. Also, we do not have information on phenotypic features related to androgen activity such as hirsutism or acne, thus we can only evaluate androgens biochemically and not clinically in this population.

\section{Menstrual Cycle Function}

Our results also show a negative relationship between vitamin D and E1G while showing a null relationship with PdG. We found no relationship between vitamin D and the risk of sporadic anovulation, menstrual cycle length, follicular phase length, and luteal phase length. It thus does not appear that vitamin D affects estrogen concentrations via ovarian follicular dynamics, as one would expect the other outcomes to differ in concert with estrogen if this were the case. If vitamin 
D does in fact drive estrogen concentrations, it could explain how it affects the bioavailability of androgens, since estrogen increases SHBG production which in turns limits bioavailability. An important limiting factor to keep in mind when reading these results is our lack of serum estradiol data. However, we believe the prospectively collected E1G from daily urine samples compensates for this shortcoming as it is directly related to estradiol concentrations and is stable in urine (64).

\section{Premenstrual Syndrome}

We found no relationship between vitamin D and overall risk of PMS. We did find a relationship between vitamin D and both breast fullness/tenderness and generalized aches and pains in the premenstrual week, which in turn drove a relationship with number of moderate/severe physical symptoms of PMS. No significant relationships were found between vitamin D and psychological symptoms of PMS.

The biological mechanism underlying the relationship between vitamin D and generalized aches and pains in PMS may be better understood by investigating diseases with symptomatology similar to those caused by hypocalcemic states. One such is aromatase inhibitor musculoskeletal symptoms (AIMSS), characterized by a cluster of musculoskeletal symptoms that include bone, muscle, and joint pain; muscle stiffness; carpal tunnel syndrome; tenosynovitis; and allodynia (62,65-70), which are also symptoms of hypocalcemic diseases like vitamin D deficiency (70-72). Given that vitamin D is used to treat AIMSS (70,73-78), there may be similar pathophysiologic mechanisms between AIMSS and generalized aches and pain in PMS. Adult dorsal root ganglia in female rats have vitamin D receptors and enzymes whose expression changes when the rats undergo oophorectomy, indicating that ovarian hormones affect expression in sensory neurons in 
these female rats (79). A similar mechanism may lead to premenstrual aches and pains modulated by [lack of] vitamin D.

It is important to note that our data is limited in that it compares vitamin D concentrations with the prevalence of PMS symptoms that were retrospectively reported over the past year. Data that prospectively compares the two might be able to more definitively establish a relationship between vitamin D and PMS symptoms.

\section{Overall Strengths and Limitations}

Overall, this was a large study among women with proven fecundity, regular cycles, and a history of prior pregnancy loss, expanding upon prior work in college-age populations and among a cohort of nurses. Further, our use of serum concentrations of vitamin D is a strength, as dietary assessments are unable to fully capture vitamin D status, and serum concentrations have been shown to be an accurate biological reflection of vitamin D status regardless of source $(80,81)$. It should be noted that over $90 \%$ of participants in EAGeR were taking vitamin supplements, and it is possible that some women were consuming supplemental vitamin D. Though we do not have data on specific vitamin formulation, our serum assessment of vitamin D should overcome this limitation. Also, all of the women in the trial were fecund and had a history of 1-2 pregnancy losses, so it might not be generalizable to all reproductive age women. Notwithstanding, a large proportion of reproductive age women have had a pregnancy loss, so implications of these results are yet nonetheless broad (82). 


\section{CONCLUSIONS}

In summary, we found relationships between serum vitamin D concentrations and SHBG, the bioavailability of androgens, and physical symptoms of PMS - specifically breast tenderness/fullness and generalized aches and pains - using data from the EAGeR trial. We also did not find a relationship between vitamin D and sporadic anovulation, menstrual cycle length, and psychological symptoms of PMS or overall risk of PMS, which is reassuring. To our knowledge, these are the first investigations into the relationships between vitamin D and androgens, anovulation, and menstrual length among healthy, regularly cycling, premenopausal women. These findings shed insights into normal physiology and may help us understand pathophysiologic processes plaguing many women worldwide. 


\section{ACKNOWLEDGEMENTS}

I would like to thank my NIH mentors, Drs. Enrique Schisterman and Sunni Mumford, for all of their support during my predoctoral fellowship. I would also like thank Dr. Matthew Connell, Dr. Lindsey Sjaarda, Dr. Neil Perkins, Dr. Keewan Kim, Dr. Rose Radin, Ukpebo Rebecca Omosigho, Tiffany Holland, Dr. Torie Plowden, Dr. Michael Bloom, Dr. Robert Silver, Dr. Brian Whitcomb, Dr. Aijun Ye for all of their help with this research. Thanks to Dr. Germaine Buck-Louis for her support and for believing in me. Thank you to Dr. Frederick Ognibene, Dr. Susan Leitman, Dr. Andrew Demidowich, Kenneth Williams, Tonya Shackelford, and Randall Smith for all of their support in the NIH Medical Research Scholars Program. Finally, thank you to Dr. Faye JusticiaLinde for all of her help in putting this together and in general for being a wonderful OB/GYN mentor.

\section{FUNDING}

This work was supported by the Intramural Research Program of the Eunice Kennedy Shriver National Institute of Child Health and Human Development, National Institutes of Health, Bethesda, Maryland (Contract Nos. HHSN267200603423, HHSN267200603424, HHSN267200603426). Daniel Kuhr was funded by the NIH Medical Research Scholars Program, a public-private partnership jointly supported by the $\mathrm{NIH}$ and generous contributions to the Foundation for the NIH by the Doris Duke Charitable Foundation (Grant \#2014194), the American Association for Dental Research, the Colgate-Palmolive Company, Genentech, and other private donors. For a complete list, visit the foundation website at http://www.fnih.org. 


\section{REFERENCES}

1. Cheng JB, Levine MA, Bell NH, Mangelsdorf DJ, Russell DW. Genetic evidence that the human CYP2R1 enzyme is a key vitamin D 25-hydroxylase. Proceedings of the National Academy of Sciences of the United States of America 2004; 101:7711-7715

2. Laing CJ, Cooke NE. Vitamin D Binding Protein. In: Feldman D, Pike WJ, Glorieux FH, eds. Vitamin D. 2 ed: Academic Press; 2005:117-134.

3. Hollis BW. Assessment of vitamin D nutritional and hormonal status: What to measure and how to do it. Calcified Tissue International 1996; 58:4-5

4. DeLuca HF, Holick MF, Schnoes HK, Suda T, Cousins RJ. Isolation and identification of 1,25-dihydroxycholecalciferol. A metabolite of vitamin $\mathrm{D}$ active in intestine. Biochemistry 1971; 10:2799-2804

5. About Vitamin D. 2011; http://vitamind.ucr.edu/about/. Accessed July 18, 2017.

6. Bouillon R, Van Cromphaut S, Carmeliet G. Intestinal calcium absorption: Molecular vitamin D mediated mechanisms. Journal of Cellular Biochemistry 2003; 88:332-339

7. Bell TD, Demay MB, Burnett-Bowie S-AM. The biology and pathology of vitamin D control in bone. Journal of Cellular Biochemistry 2010; 111:7-13

8. Johnson LE, DeLuca HF. Reproductive defects are corrected in vitamin d-deficient female rats fed a high calcium, phosphorus and lactose diet. The Journal of nutrition 2002; 132:2270-2273

9. Norman AW. From vitamin D to hormone D: fundamentals of the vitamin D endocrine system essential for good health. The American journal of clinical nutrition 2008; 88:491S-499S

10. Luk J, Torrealday S, Neal Perry G, Pal L. Relevance of vitamin D in reproduction. Hum Reprod 2012; 27:3015-3027

11. Kinuta K, Tanaka H, Moriwake T, Aya K, Kato S, Seino Y. Vitamin D is an important factor in estrogen biosynthesis of both female and male gonads. Endocrinology 2000; 141:1317-1324

12. Halhali A, Acker GM, Garabedian M. 1,25-Dihydroxyvitamin D3 induces in vivo the decidualization of rat endometrial cells. Journal of reproduction and fertility 1991; 91:5964

13. Hurley WL, Doane RM. Recent developments in the roles of vitamins and minerals in reproduction. Journal of dairy science 1989; 72:784-804

14. Holick MF, Binkley NC, Bischoff-Ferrari HA, Gordon CM, Hanley DA, Heaney RP, Murad MH, Weaver CM. Evaluation, treatment, and prevention of vitamin D deficiency: an Endocrine Society clinical practice guideline. The Journal of clinical endocrinology and metabolism 2011; 96:1911-1930

15. Forrest KY, Stuhldreher WL. Prevalence and correlates of vitamin D deficiency in US adults. Nutrition research (New York, NY) 2011; 31:48-54

16. Gagnon C, Baillargeon J-P, Desmarais G, Fink GD. Prevalence and predictors of vitamin $\mathrm{D}$ insufficiency in women of reproductive age living in northern latitude. European Journal of Endocrinology 2010; 163:819-824

17. Bodnar LM, Simhan HN, Powers RW, Frank MP, Cooperstein E, Roberts JM. High Prevalence of Vitamin D Insufficiency in Black and White Pregnant Women Residing in the Northern United States and Their Neonates. The Journal of nutrition 2007; 137:447452 
18. Polycystic Ovary Syndrome (PCOS). 2016; http://www.aesociety.org/pdf/handouts/pcos.pdf. Accessed July 27, 2017.

19. Infertility Fact Sheet. In: Office on Women's Health USDoHaHS, ed. Washington, D.C.2012.

20. Ganie MA, Marwaha RK, Nisar S, Farooqi KJ, Jan RA, Wani SA, Gojwari T, Shah ZA. Impact of hypovitaminosis D on clinical, hormonal and insulin sensitivity parameters in normal body mass index polycystic ovary syndrome women. Journal of Obstetrics and Gynaecology 2016; 36:508-512

21. Dravecka I, Figurova J, Javorsky M, Petrikova J, Val'kova M, Lazurova I. The Effect of Alfacalcidiol and Metformin on Phenotype Manifestations in Women with Polycystic Ovary Syndrome - a Preliminary Study. Physiological Research 2016; 65:815-822

22. Mason C, Tapsoba JD, Duggan C, Imayama I, Wang CY, Korde LA, Stanczyk F, McTiernan A. Effects of vitamin D supplementation during weight loss on sex hormones in postmenopausal women. Menopause-the Journal of the North American Menopause Society 2016; 23:645-652

23. Zhao D, Ouyang P, de Boer IH, Lutsey PL, Farag YMK, Guallar E, Siscovick DS, Post WS, Kalyani RR, Billups KL, Michos ED. Serum vitamin D and sex hormones levels in men and women: The Multi-Ethnic Study of Atherosclerosis (MESA). Maturitas 2017; 96:95-102

24. Hammond GL. Diverse Roles for Sex Hormone-Binding Globulin in Reproduction1. Biology of Reproduction 2011; 85:431-441

25. Zgliczyński JKARKAW. Associations of vitamin D concentration with metabolic and hormonal indices in women with polycystic ovary syndrome presenting abdominal and gynoidal type of obesity. Vol 85.

26. Wehr E, Pilz S, Schweighofer N, Giuliani A, Kopera D, Pieber TR, Obermayer-Pietsch B. Association of hypovitaminosis D with metabolic disturbances in polycystic ovary syndrome. European Journal of Endocrinology 2009; 161:575-582

27. El maataoui A, El Maghraoui A, Biaz A, Elmachtani SI, Dami A, Bouhsain S, Mounach A, Chabraoui L, Ouzzif Z. Relationships between vertebral fractures, sex hormones and vitamin D in Moroccan postmenopausal women: a cross sectional study. BMC Women's Health 2015; $15: 41$

28. Mahmoudi T. Genetic variation in the vitamin D receptor and polycystic ovary syndrome risk. Fertility and Sterility 2009; 92:1381-1383

29. Wehr E, Trummer O, Giuliani A, Gruber H-J, Pieber TR, Obermayer-Pietsch B. Vitamin D-associated polymorphisms are related to insulin resistance and vitamin D deficiency in polycystic ovary syndrome. European Journal of Endocrinology 2011; 164:741-749

30. Zadeh-Vakili A, Ramezani Tehrani F, Daneshpour MS, Zarkesh M, Saadat N, Azizi F. Genetic polymorphism of vitamin D receptor gene affects the phenotype of PCOS. Gene 2013; 515:193-196

31. Ranjzad F, Mahban A, Irani Shemirani A, Mahmoudi T, Vahedi M, Nikzamir A, Zali MR. Influence of gene variants related to calcium homeostasis on biochemical parameters of women with polycystic ovary syndrome. Journal of Assisted Reproduction and Genetics 2011;28:225-232

32. Jayagopal V, Kilpatrick ES, Jennings PE, Hepburn DA, Atkin SL. The Biological Variation of Testosterone and Sex Hormone-Binding Globulin (SHBG) in Polycystic 
Ovarian Syndrome: Implications for SHBG as a Surrogate Marker of Insulin Resistance. The Journal of Clinical Endocrinology \& Metabolism 2003; 88:1528-1533

33. Perez-Fernandez R, Alonso M, Segura C, Munoz I, Garcia-Caballero T, Diguez C. Vitamin D receptor gene expression in human pituitary gland. Life sciences 1997; 60:3542

34. Chavarro JE, Rich-Edwards JW, Rosner B, Willett WC. A prospective study of dairy foods intake and anovulatory infertility. Hum Reprod 2007; 22:1340-1347

35. Rashidi B, Haghollahi F, Shariat M, Zayerii F. The effects of calcium-vitamin D and metformin on polycystic ovary syndrome: a pilot study. Taiwanese journal of obstetrics \& gynecology 2009; 48:142-147

36. Firouzabadi Rd, Aflatoonian A, Modarresi S, Sekhavat L, MohammadTaheri S. Therapeutic effects of calcium \&amp; vitamin D supplementation in women with PCOS. Complementary Therapies in Clinical Practice 2012; 18:85-88

37. Lynch KE, Mumford SL, Schliep KC, Whitcomb BW, Zarek SM, Pollack AZ, BertoneJohnson ER, Danaher M, Wactawski-Wende J, Gaskins AJ, Schisterman EF. Assessment of Anovulation in Eumenorrheic Women: Comparison of Ovulation Detection Algorithms. Fertility and sterility 2014; 102:511-518.e512

38. Infertility Fact Sheet. 2012; https://www.womenshealth.gov/publications/ourpublications/fact-sheet/infertility.html.

39. Mumford SL, Steiner AZ, Pollack AZ, Perkins NJ, Filiberto AC, Albert PS, Mattison DR, Wactawski-Wende J, Schisterman EF. The Utility of Menstrual Cycle Length as an Indicator of Cumulative Hormonal Exposure. The Journal of clinical endocrinology and metabolism 2012; 97:E1871-E1879

40. Jukic AM, Upson K, Harmon QE, Baird DD. Increasing serum 25-hydroxyvitamin D is associated with reduced odds of long menstrual cycles in a cross-sectional study of African American women. Fertility and sterility 2016; 106:172-179.e172

41. Jukic AMZ, Steiner AZ, Baird DD. Lower plasma 25-hydroxyvitamin D is associated with irregular menstrual cycles in a cross-sectional study. Reproductive Biology and Endocrinology 2015; 13:20

42. Rashidi B, Haghollahi F, Shariat M, Zayerii F. The Effects of Calcium-Vitamin D and Metformin on Polycystic Ovary Syndrome: A Pilot Study. Taiwanese Journal of Obstetrics and Gynecology 2009; 48:142-147

43. Thys-Jacobs S, Donovan D, Papadopoulos A, Sarrel P, Bilezikian JP. Vitamin D and calcium dysregulation in the polycystic ovarian syndrome. Steroids 1999; 64:430-435

44. Sirmans SM, Pate KA. Epidemiology, diagnosis, and management of polycystic ovary syndrome. Clinical Epidemiology 2014; 6:1-13

45. Direkvand-Moghadam A, Sayehmiri K, Delpisheh A, Kaikhavandi S. Epidemiology of Premenstrual Syndrome (PMS)-A Systematic Review and Meta-Analysis Study. Journal of clinical and diagnostic research : JCDR 2014; 8:106-109

46. Johnson SR. Premenstrual syndrome, premenstrual dysphoric disorder, and beyond: a clinical primer for practitioners. Obstetrics and gynecology 2004; 104:845-859

47. Halbreich U, Borenstein J, Pearlstein T, Kahn LS. The prevalence, impairment, impact, and burden of premenstrual dysphoric disorder (PMS/PMDD).

Psychoneuroendocrinology 2003; 28 Suppl 3:1-23 
48. Sternfeld B, Swindle R, Chawla A, Long S, Kennedy S. Severity of premenstrual symptoms in a health maintenance organization population. Obstetrics and gynecology 2002; 99:1014-1024

49. Schafer AS, DM. Hypocalcemia: Diagnosis and Treatment. South Dartmouth, MA: MDText.com.

50. Thys-Jacobs S. Micronutrients and the premenstrual syndrome: The case for calcium. Journal of the American College of Nutrition 2000; 19:220-227

51. Lasco A, Catalano A, Benvenga S. Improvement of primary dysmenorrhea caused by a single oral dose of vitamin d: Results of a randomized, double-blind, placebo-controlled study. Archives of Internal Medicine 2012; 172:366-367

52. Krishnan AV, Feldman D. Mechanisms of the anti-cancer and anti-inflammatory actions of vitamin D. Annual review of pharmacology and toxicology 2011; 51:311-336

53. Thota C, Farmer T, Garfield RE, Menon R, Al-Hendy A. Vitamin D elicits antiinflammatory response, inhibits contractile-associated proteins, and modulates Toll-like receptors in human myometrial cells. Reproductive sciences (Thousand Oaks, Calif) 2013; 20:463-475

54. Schisterman EF, Silver RM, Perkins NJ, Mumford SL, Whitcomb BW, Stanford JB, Lesher LL, Faraggi D, Wactawski-Wende J, Browne RW, Townsend JM, White M, Lynch AM, Galai N. A randomised trial to evaluate the effects of low-dose aspirin in gestation and reproduction: design and baseline characteristics. Paediatric and perinatal epidemiology 2013; 27:598-609

55. Sartorius G, Ly LP, Sikaris K, McLachlan R, Handelsman DJ. Predictive accuracy and sources of variability in calculated free testosterone estimates. Annals of clinical biochemistry 2009; 46:137-143

56. Johnson S, Weddell S, Godbert S, Freundl G, Roos J, Gnoth C. Development of the first urinary reproductive hormone ranges referenced to independently determined ovulation day. Clinical chemistry and laboratory medicine 2015; 53:1099-1108

57. Park SJ, Goldsmith LT, Skurnick JH, Wojtczuk A, Weiss G. Characteristics of the urinary luteinizing hormone surge in young ovulatory women. Fertil Steril 2007; 88:684690

58. Behre HM, Kuhlage J, Gaßner C, Sonntag B, Schem C, Schneider HPG, Nieschlag E. Prediction of ovulation by urinary hormone measurements with the home use ClearPlan ${ }^{\circledR}$ Fertility Monitor: comparison with transvaginal ultrasound scans and serum hormone measurements. Hum Reprod 2000; 15:2478-2482

59. Borenstein JE, Dean BB, Endicott J, Wong J, Brown C, Dickerson V, Yonkers KA. Health and economic impact of the premenstrual syndrome. The Journal of reproductive medicine 2003; 48:515-524

60. Borenstein JE, Dean BB, Yonkers KA, Endicott J. Using the daily record of severity of problems as a screening instrument for premenstrual syndrome. Obstetrics and gynecology 2007; 109:1068-1075

61. Gollenberg AL, Hediger ML, Mumford SL, Whitcomb BW, Hovey KM, WactawskiWende J, Schisterman EF. Perceived stress and severity of perimenstrual symptoms: the BioCycle Study. Journal of women's health (2002) 2010; 19:959-967

62. Crew KD, Greenlee H, Capodice J, Raptis G, Brafman L, Fuentes D, Sierra A, Hershman DL. Prevalence of Joint Symptoms in Postmenopausal Women Taking Aromatase 
Inhibitors for Early-Stage Breast Cancer. Journal of Clinical Oncology 2007; 25:38773883

63. Principles and Practice of Endocrinology and Metabolism. 3 ed: Lippincott Williams \& Wilkins.

64. Wishart DS, Jewison T, Guo AC, Wilson M, Knox C, Liu Y, Djoumbou Y, Mandal R, Aziat F, Dong E, Bouatra S, Sinelnikov I, Arndt D, Xia J, Liu P, Yallou F, Bjorndahl T, Perez-Pineiro R, Eisner R, Allen F, Neveu V, Greiner R, Scalbert A. HMDB 3.0--The Human Metabolome Database in 2013. Nucleic acids research 2013; 41:D801-807

65. Morales L, Pans S, Verschueren K, Calster BV, Paridaens R, Westhovens R, Timmerman D, Smet LD, Vergote I, Christiaens M-R, Neven P. Prospective Study to Assess ShortTerm Intra-Articular and Tenosynovial Changes in the Aromatase Inhibitor-Associated Arthralgia Syndrome. Journal of Clinical Oncology 2008; 26:3147-3152

66. Fusi C, Materazzi S, Benemei S, Coppi E, Trevisan G, Marone IM, Minocci D, De Logu F, Tuccinardi T, Di Tommaso MR, Susini T, Moneti G, Pieraccini G, Geppetti P, Nassini R. Steroidal and non-steroidal third-generation aromatase inhibitors induce pain-like symptoms via TRPA1. 2014; 5:5736

67. Lintermans A, Laenen A, Van Calster B, Van Hoydonck M, Pans S, Verhaeghe J, Westhovens R, Henry NL, Wildiers H, Paridaens R, Dieudonné AS, Leunen K, Morales L, Verschueren K, Timmerman D, De Smet L, Vergote I, Christiaens MR, Neven P. Prospective study to assess fluid accumulation and tenosynovial changes in the aromatase inhibitor-induced musculoskeletal syndrome: 2-year follow-up data. Annals of Oncology 2013; 24:350-355

68. Niravath P. Aromatase inhibitor-induced arthralgia: a review. Annals of Oncology 2013; 24:1443-1449

69. Mao JJ, Stricker C, Bruner D, Xie S, Bowman MA, Farrar JT, Greene BT, DeMichele A. Patterns and risk factors associated with aromatase inhibitor-related arthralgia among breast cancer survivors. Cancer 2009; 115:3631-3639

70. Shapiro AC, Adlis SA, Robien K, Kirstein MN, Liang S, Richter SA, Lerner RE. Randomized, blinded trial of vitamin D3 for treating aromatase inhibitor-associated musculoskeletal symptoms (AIMSS). Breast Cancer Research and Treatment 2016; 155:501-512

71. Holick MF. High Prevalence of Vitamin D Inadequacy and Implications for Health. Mayo Clinic Proceedings 2006; 81:353-373

72. Glerup H, Mikkelsen K, Poulsen L, Hass E, Overbeck S, Andersen H, Charles P, Eriksen EF. Hypovitaminosis D myopathy without biochemical signs of osteomalacic bone involvement. Calcified tissue international 2000; 66:419-424

73. Khan QJ, Kimler BF, Reddy PS, Sharma P, Klemp JR, Fabian CJ. Randomized trial of vitamin D3 to prevent worsening of musculoskeletal symptoms and fatigue in women with breast cancer starting adjuvant letrozole: The VITAL trial. Journal of Clinical Oncology 2012; 30:9000-9000

74. Rastelli AL, Taylor ME, Gao F, Armamento-Villareal R, Jamalabadi-Majidi S, Napoli N, Ellis MJ. Vitamin D and aromatase inhibitor-induced musculoskeletal symptoms (AIMSS): a phase II, double-blind, placebo-controlled, randomized trial. Breast Cancer Research and Treatment 2011; 129:107-116

75. Prieto-Alhambra D, Javaid MK, Servitja S, Arden NK, Martinez-García M, Diez-Perez A, Albanell J, Tusquets I, Nogues X. Vitamin D threshold to prevent aromatase inhibitor- 
induced arthralgia: a prospective cohort study. Breast Cancer Research and Treatment $2011 ; 125: 869-878$

76. Singer O, Cigler T, Moore AB, Levine AB, Do HT, Mandl LA. Hypovitaminosis D is a Predictor of Aromatase Inhibitor Musculoskeletal Symptoms. The Breast Journal 2014; 20:174-179

77. Khan QJ, Reddy PS, Kimler BF, Sharma P, Baxa SE, O’Dea AP, Klemp JR, Fabian CJ. Effect of vitamin D supplementation on serum 25-hydroxy vitamin D levels, joint pain, and fatigue in women starting adjuvant letrozole treatment for breast cancer. Breast Cancer Research and Treatment 2009; 119:111

78. Waltman NL, Ott CD, Twiss JJ, Gross GJ, Lindsey AM. Vitamin D Insufficiency and Musculoskeletal Symptoms in Breast Cancer Survivors on Aromatase Inhibitor Therapy. Cancer Nursing 2009; 32:143-150

79. Tague SE, Smith PG. Vitamin D receptor and enzyme expression in dorsal root ganglia of adult female rats: Modulation by ovarian hormones. Journal of Chemical Neuroanatomy 2011; 41:1-12

80. Takeuchi A, Okano T, Ishida Y, Kobayashi T. Effects of dietary vitamin D intake on plasma levels of parathyroid hormone and vitamin D metabolites in healthy Japanese. Mineral and electrolyte metabolism 1995; 21:217-222

81. Thomas MK, Lloyd-Jones DM, Thadhani RI, Shaw AC, Deraska DJ, Kitch BT, Vamvakas EC, Dick IM, Prince RL, Finkelstein JS. Hypovitaminosis D in medical inpatients. The New England journal of medicine 1998; 338:777-783

82. How many people are affected by or at risk for pregnancy loss or miscarriage? Pregnancy Loss https://www.nichd.nih.gov/health/topics/pregnancyloss/conditioninfo/Pages/risk.aspx. Accessed July 23, 2017. 